\title{
AN ANALYSIS OF BITCOIN ACCEPTANCE IN INDONESIA
}

\author{
Fergyanto E. Gunawan ${ }^{1}$ and Rizki Novendra ${ }^{2}$ \\ ${ }^{1,2,3}$ Industrial Engineering Department, BINUS Graduate Program - Master of Industrial Engineering, \\ Bina Nusantara University \\ Jln. Kebon Jeruk Raya No. 27, Jakarta Barat 11530, Indonesia \\ 1'fgunawan@binus.edu; ${ }^{2}$ rizki_novendr4@yahoo.com
}

Received: $9^{\text {th }}$ August 2017/ Revised: $18^{\text {th }}$ August 2017/ Accepted: $9^{\text {th }}$ September 2017

\begin{abstract}
This research intended to understand the factors affecting the acceptance of Bitcoin technology in Indonesia. It adopted the model of Unified Theory of Acceptance and Use of Technology (UTAUT), which took into account four influencing factors. Those were performance expectancy, effort expectancy, social influence, and facilitating conditions. The factors of gender and age were assumed to moderate the relations between those four factors and use and behavioral intention. The empirical data for those factors were collected by questionnaires from 49 respondents. The statistical significance of the relationships was evaluated by multivariate regression analysis. The result is a model that matches the data with $\mathrm{R} 2=0,678$. It demonstrates a high level of fitness. The analysis suggests that the performance expectancy factor and the social influence factor greatly affect the behavioral intention to use Bitcoin with the values of t-statistic of 3,835 (p-value $=0,000)$ for the former factor and $1,948(0,059)$ for the latter factor. However, the social influence factor has less profound effect on the behavioral intention.
\end{abstract}

Keywords: Bitcoin, Unified Theory of Acceptance and Use of Technology (UTAUT), Indonesia, cryptocurrency

\section{INTRODUCTION}

The today rapidly growing Internet development has opened up many new technologies in the world including the digital currency called Bitcoin. Bitcoin is a decentralized financial protocol based on the peer-to-peer network. It is capable of connecting any computer throughout the world for establishing an open accounting book (Feld, Schönfeld, $\&$ Werner, 2014). In other words, Bitcoin is a new payment transaction system where the money is in digital form. By using Bitcoin, anyone is able to send money to anywhere instantly. The Bitcoin digital currency can also be used for many types of online and offline transactions. Up to this point in time, the use of Bitcoin as the digital currency is rather limited. Bitcoin was established by anonymous who referred to himself as Satoshi Nakamoto in November 2008. It is not known what may be the reason for the Bitcoin's founder to conceal his identity.

Some data show that Indonesians have been using Bitcoin since the end of 2013. It does not take a long time for Bitcoin's presence in the financial world to be discovered and supported by online and print media. Bitcoin keeps growing in Indonesia as shown in the data depicted in Figure 1. Currently, the number of Bitcoin users in Indonesia has exceeded 36.891 people.

The Bitcoin development continues to increase. It is not only in the number of users but also in the exchange rate of Bitcoin against Rupiah, the Indonesia currency. As of June 2016, Bitcoin exchange rate against Rupiah had reached a high record of Rp10,3956 million. Figure 2 shows the dynamics of the exchange rates on the first semester of 2016.

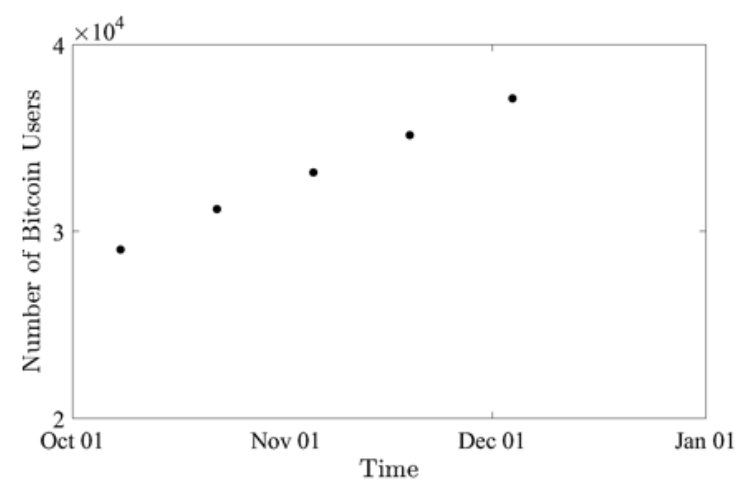

Figure 1 The Increasing Number of the Bitcoin Users in Indonesia in 2015

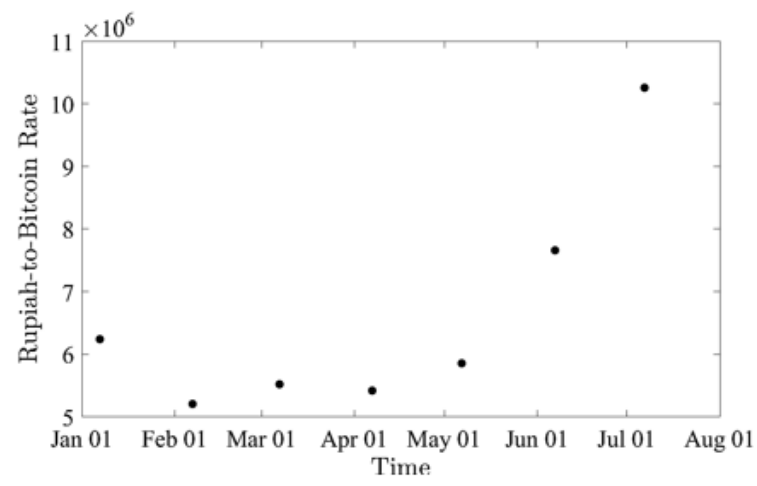

Figure 2 Bitcoin Exchange Rate against Rupiah in 2016

There are several websites in Indonesia that are dedicated to serve Bitcoin. One of them is www.bitcoin. co.id. They provide rather similar facilities related to Bitcoin such as the information of buying and selling, receiving, sending, depositing, and withdrawing. In Figure 3 , people can see a simple user interface from a Bitcoin site to facilitate depositing in Bitcoin. To use Bitcoin, people have to register firstly on those sites.

Bitcoin offers some benefits over the traditional currency. It can save plenty of the time of transactions as it does not require traders. The transactions can be made anywhere irrespective of the national boundaries. Thus, 
business entities find this feature to be the most relevant to their needs (Abdulwahab \& Dahalin, 2010). Anonymous transactions can be made using Bitcoin. For the reason, Bitcoin is widely used in the transactions on the deep web or darknet such as buying non-prescription medicines or even illegal weapons. In using Bitcoin, once the transaction has been made, it cannot be canceled unilaterally.

There are several previous researches about Bitcoin. Fleder, Kester, and Pillai (2015) analyzed about the level of anonymity in the Bitcoin system. They used two-fold approach. First, they linked the Bitcoin public keys to real people. Second, they used graph-analysis framework to find activity of both known and unknown users. The results showed that by analyzing several sources of publicly available information via web-scraped forums and Bitcoin's transaction ledger, the Bitcoin transaction was not fully unknown.

Then, Bohr and Bashir (2014) presented an exploratory analysis of Bitcoin users. They agreed that Bitcoin might have future challenges and financial powers through its decentralized structure. Bitcoin might offer instant and anonymous transactions. They analyzed the structure of the Bitcoin community by using several factors. Those were optimism about the future of Bitcoin, wealth accumulation, and themes that attracted users to the cryptocurrency. The results showed that age, time of initial use, mining status, engaging online discourse, geographic location, and political orientation were related that helped many aspects of Bitcoin wealth, attraction, and optimism.

Next, Moore and Christian (2013) saw the risk that investors had to face from Bitcoin exchanges. They used the track record of 40 Bitcoin exchanges. Using a proportional hazards model, they implied that an exchange's transaction volume indicated whether or not it would close. Less popular exchanges could shut faster than the popular ones.

Androulaki et al. (2013) wanted to analyze the users' privacy guarantees in Bitcoin if Bitcoin was in the daily transactions and used as the primary currency. After analyzing the current strategy used by Bitcoin for the user's privacy, the researchers found out, it was not enough. They suggested Bitcoin should work with the trusted third-party company to increase the privacy. By having the trusted third-party company, the large data of transactions could be hidden well. Thus, the users' privacy could be increased. However, this suggestion might clash with the main principle of Bitcoin as the decentralized system.

According to Scott (2016), Bitcoin is widely used in ten countries. Those are Estonia, United States, Denmark, Sweden, South Korea, Netherlands, Finland, Canada, England, and Australia. It can be used in many shopping stores and hotels. Moreover, Bitcoin ATMs are widely available. That evidence suggests that Bitcoin has been widely accepted in those ten countries. However, the level of acceptance has not been found in Indonesia. Therefore, this research intends to study what factors that are considered important to use Bitcoin technology in Indonesia.

\section{METHODS}

The present research discusses the technology acceptance of Bitcoin and the extent of the users' trust in Indonesia. The Bitcoin acceptance evaluation is performed by adopting the Unified Theory of Acceptance and Use of Technology (UTAUT) framework, which has been widely used in many technology acceptance studies (Abdulwahab \& Dahalin, 2010; Rogojanu \& Badea, 2014; Davis, 1989;
Venkatesh et al., 2003; Fathema, Shannon, \& Ross, 2015; Silinskyte, 2014).

As known previously, Bitcoin is a digital currency that has an open source and a peer-to-peer system. Bitcoin was founded in 2008 by an anonymous, Satoshi Nakamoto (Rogojanu \& Badea, 2014). In line with the development of technology and the ease of the Internet access today, it provides the opportunity to use Bitcoin for Indonesians. The question arises on whether Bitcoin technology may have a good acceptance level in Indonesia, and what are the influencing factors.

\begin{tabular}{l} 
Step 1: Info Dana \\
Lengkapi informasi deposit di bawah: \\
Jumlah Deposit: \\
Sumber Dana: \\
Jumlah Setoran dalam Rupiah \\
Bank Central Asia (BCA) \\
Nomor Rekening Anda: \\
\hline MTM BCA
\end{tabular}

Figure 3 An Example of the Easy-to-Use Users' Interface for Depositing Bitcoin

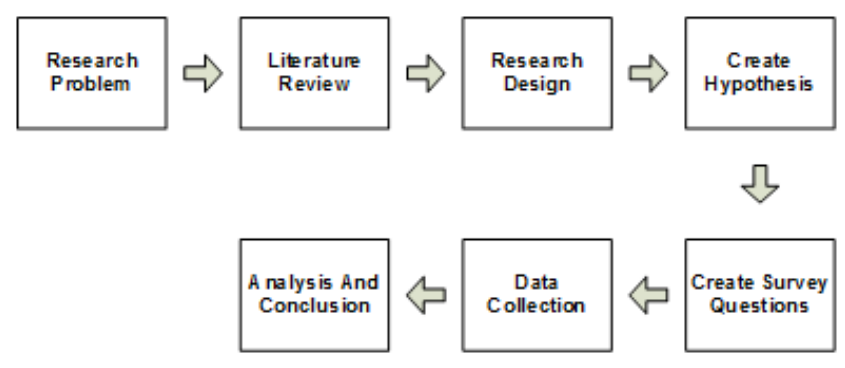

Figure 4 The Research Procedure

This research intends to measure the factors affecting the acceptance technology in Indonesia. For this purpose, UTAUT model is adopted and utilized. The model is developed on the basis of the eight earlier acceptance theories and has four core dimensions (Davis, 1989; Venkatesh et al., 2003; Fathema, Shannon, \& Ross, 2015; Silinskyte, 2014). The research procedure is shown in Figure 4.

A brief description of each block in the research procedures depicted in Figure 4 is explained. The research begins with the block research problem, where the issue is defined in detail. The researchers are interested in understanding the level of acceptance of the Bitcoin technology in Indonesia. Specifically, the acceptance level will be measured by using UTAUT framework. It stipulates the acceptance of new technology as a factor depending on four constructs. Those are performance expectancy, effort expectancy, social influence, and facilitating conditions. Moreover, the next block is literature review. It is performed to understand the UTAUT framework and previous studies related to Bitcoin technology from the user 
acceptance aspects. The following block is research design. The procedure of understanding the acceptance level is defined in detail including the data collection and analysis method. In the block hypotheses, the research problem is expressed into twelve hypotheses. Those will be evaluated by collecting empirical data and statistical analysis. In addition, questionnaires are established and distributed to obtain the data regarding the constructs: such as performance expectancy, effort expectancy, social influence, facilitating conditions, behavioral intention, and use behavior. Then, the data of two moderating variables, gender and age, are also collected. On the analysis and conclusion block, a statistical analysis will be performed from which the conclusions regarding the twelve hypotheses will be taken.

The UTAUT framework is reproduced from Venkatesh et al. (2003) in Figure 5. Moreover, Figure 6 shows the hypothesis structure within the UTAUT framework. The structure is broken down into twelve hypotheses. Those 12 hypotheses are of the following.

$\mathrm{H} 1$ = Performance expectancy has a positive effect on behavior intention.

$\mathrm{H} 2$ = Performance expectancy and behavior intention relation are moderated by gender.

$\mathrm{H} 3$ = Performance expectancy and behavior intention relation are moderated by age.

$\mathrm{H} 4=$ Effort expectancy has a positive effect on behavior intention.

$\mathrm{H} 5=$ Effort expectancy and behavior intention relation are moderated by gender.

H6 = Effort expectancy and behavior intention relation are moderated by age.

$\mathrm{H} 7=$ Social influence has a positive effect on behavior intention.

$\mathrm{H} 8=$ Social influence and behavior intention relation are moderated by gender.

$\mathrm{H} 9=$ Social influence and behavior intention relation are moderated by age.

$\mathrm{H} 10=$ Facilitating condition has a positive effect on use behavior.

H11 = Facilitating condition and use behavior relation is moderated by age.

$\mathrm{H} 12$ = Behavioral intention has a positive effect on use behavior.

Furthermore, the data for the current research are collected by using online questionnaires, which are distributed to more than 100 Bitcoin users. Those users are active in Indonesia Bitcoin Forum at www.forumbitcoin. co.id and www.bitcoin.co.id. The questions are provided in Indonesia language. The respondent responses are collected from October 25, 2016, until November 30, 2016. In total, the responses from 49 respondents are successfully administered. For example, a screenshot of a part of the questionnaire is shown in Figure 7.

The level of the statistical significance of the relationships is depicted in Figure 6. It is evaluated by using the multivariate regression analysis. The readers are advised to read Lungan (2006) for the detail of the method. In brief, the model depicted in Figure 6 is mathematically expressed as a linear model. It leads to the behavioral intention and use behavior factors. The influences of the four independent factors, namely, performance expectancy, effort expectancy, social influence, and facilitation conditions are assumed proportional to weight factors computed by using the leastsquares method.

Prior the use of the regression model, the model validity is carefully assessed. The F-statistic and t-statistics are computed to evaluate the significance of the model coefficients. The residual data of the model are observed from the perspective of the randomness, homoscedasticity, and normal distribution. When the regression model is satisfactory, it is used to assess the stated hypotheses.

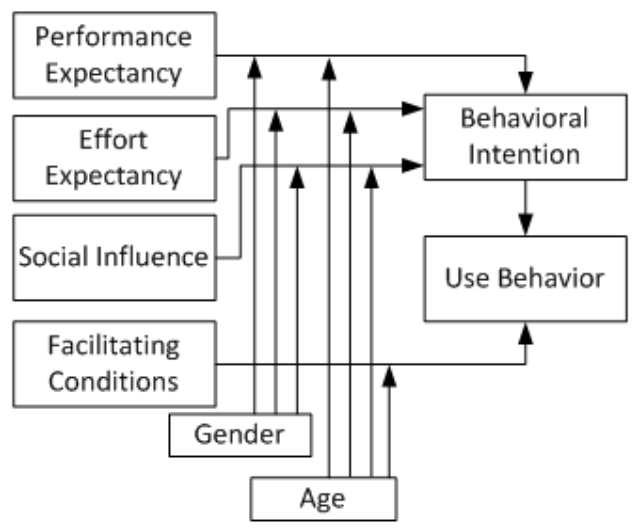

Figure 5 The Adopted Unified Theory of Acceptance and Use of Technology (UTAUT) Model Where Only Two

Factors are Assumed to Moderate the Relationships, Namely, Gender and Age (Source: Venkatesh et al., 2003)

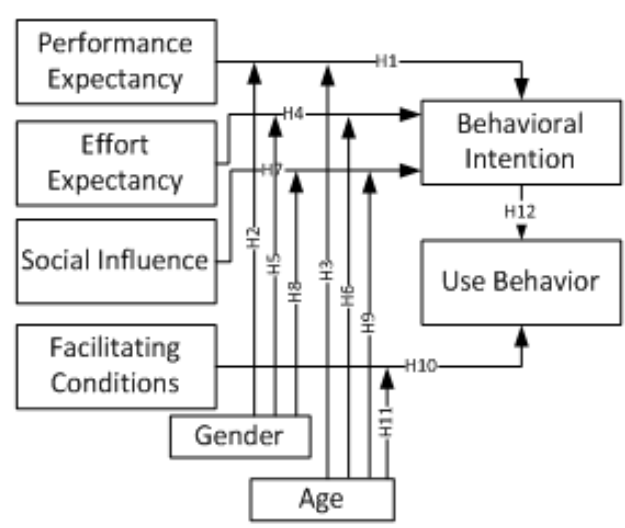

Figure 6 The Structure of the Twelve Hypotheses in the Current Research

\section{RESULTS AND DISCUSSIONS}

The characteristics of 49 respondents are various. From the 49 respondents, 45 (92\%) of them are male, and only four ( $8 \%$ ) are female (see Figure 8 ). It can imply that the Indonesia Bitcoin users are heavily dominated by male. For the respondent age, 25 respondents (59\%) are within 20 to 25 years old. Only 20 respondents $(41 \%)$ are older than 26 years old (see Figure 9). Four woman respondents are within 20 to 25 years old. 


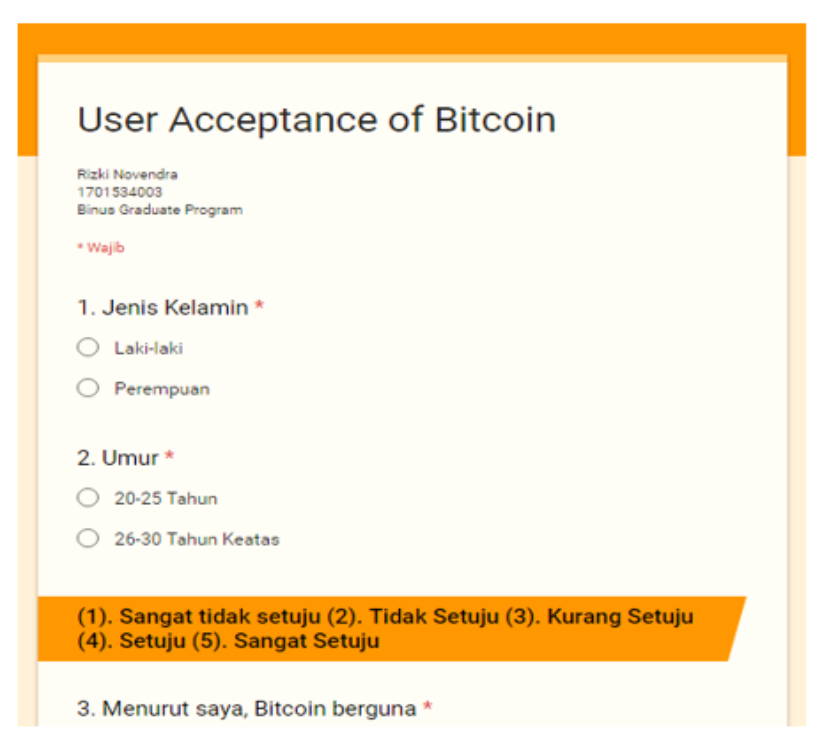

Figure 7 The Header of the Google Doc Questionnaire

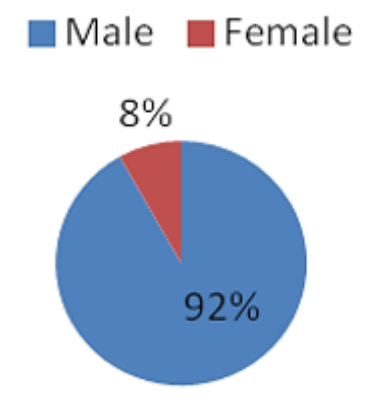

Figure 8 The Gender Distribution of the Respondents

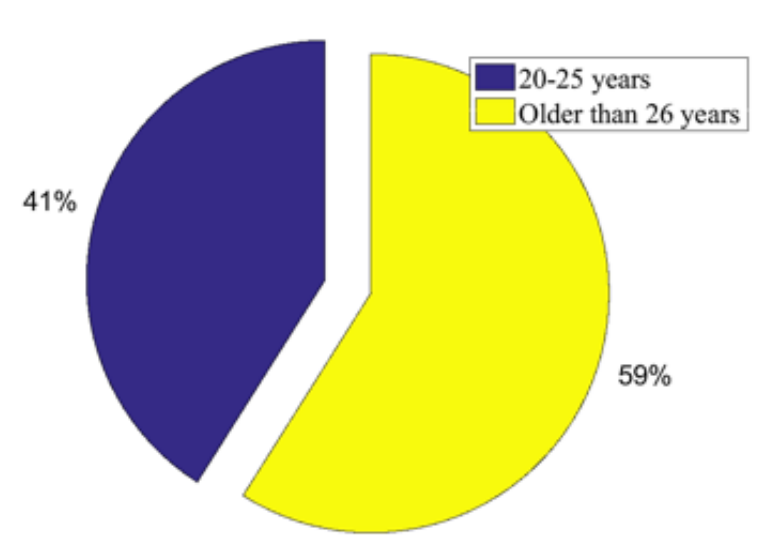

Figure 9 The Age Distribution of the Respondents

Firstly, the researchers discuss the validity of the questions in measuring all constructs. In this case, the researchers compare the r-count to the r-table. As far as the r-count is greater than $\mathrm{r}$-table, the questions are considered reliable. The results of the validity assessments are presented in Tables 1-6. Those are for the constructs such as performance expectancy, effort expectancy, social influence, facilitating condition, behavior intention, and use behavior respectively. It appears in all the results that the r-count values are much bigger than r-table. It can be concluded that the instrument is valued to measure the designated constructs.

Table 1 The Validity of the Questions Related to Performance Expectancy

\begin{tabular}{ccccc}
\hline Question & \#Respondents & $r$-count & $r$-table & Status \\
\hline PE 1 & 49 & 0,895 & 0,281 & Valid \\
PE 2 & 49 & 0,832 & 0,281 & Valid \\
PE 3 & 49 & 0,853 & 0,281 & Valid \\
PE 4 & 49 & 0,871 & 0,281 & Valid \\
PE 5 & 49 & 0,912 & 0,281 & Valid \\
\hline
\end{tabular}

Table 2 The Validity of the Questions Related to Effort Expectancy

\begin{tabular}{ccccc}
\hline Question & \#Respondents & $r$-count & $r$-table & Status \\
\hline EE 1 & 49 & 0,888 & 0,281 & Valid \\
EE 2 & 49 & 0,926 & 0,281 & Valid \\
EE 3 & 49 & 0,868 & 0,281 & Valid \\
EE 4 & 49 & 0,907 & 0,281 & Valid \\
EE 5 & 49 & 0,888 & 0,281 & Valid \\
\hline
\end{tabular}

Table 3 The Validity of the Questions Related to Social Influence

\begin{tabular}{ccccc}
\hline Question & \#Respondents & $r$-count & $r$-table & Status \\
\hline SI 1 & 49 & 0,827 & 0,281 & Valid \\
SI 2 & 49 & 0,811 & 0,281 & Valid \\
SI 3 & 49 & 0,903 & 0,281 & Valid \\
\hline
\end{tabular}

Table 4 The Validity of the Questions Related to Facilitating Condition

\begin{tabular}{ccccc}
\hline Question & \#Respondents & $r$-count & $r$-table & Status \\
\hline FC 1 & 49 & 0,913 & 0,281 & Valid \\
FC 2 & 49 & 0,912 & 0,281 & Valid \\
FC 3 & 49 & 0,869 & 0,281 & Valid \\
FC 4 & 49 & 0,926 & 0,281 & Valid \\
\hline
\end{tabular}

Table 5 The Validity of the Questions Related to Behaviour Intention

\begin{tabular}{ccccc}
\hline Question & \#Respondents & $r$-count & $r$-table & Status \\
\hline BI 1 & 49 & 0,892 & 0,281 & Valid \\
BI 2 & 49 & 0,911 & 0,281 & Valid \\
BI 3 & 49 & 0,937 & 0,281 & Valid \\
\hline
\end{tabular}


Table 6 The Validity of the Questions Related to Use Behaviour

\begin{tabular}{ccccc}
\hline Question & \#Respondents & $r$-count & $r$-table & Status \\
\hline BI 1 & 49 & 0,892 & 0,281 & Valid \\
BI 3 & 49 & 0,937 & 0,281 & Valid \\
\hline
\end{tabular}

Table 7 The Results of the Reliability Analysis of the Questionnaires

\begin{tabular}{clcc}
\hline No & \multicolumn{1}{c}{ Construct } & Cronbach Alpha & Status \\
\hline 1 & Performance Expectancy & 0,898 & Reliable \\
2 & Effort Expectancy & 0,905 & Reliable \\
3 & Social Influence & 0,950 & Reliable \\
4 & Facilitating Condition & 0,905 & Reliable \\
5 & Behavior Intention & 0,900 & Reliable \\
6 & Use Behavior & 0,898 & Reliable \\
\hline
\end{tabular}

In the addition to the assessments on the questionnaire's validity, the researchers also evaluate its reliability. The Cronbach alpha is used to measure the level of reliability. The results are presented in Table 7 . The results show that the Cronbach alpha values are within the range of 0,898 and 0,905 . Those are much higher than the critical value of 0,7 . Therefore, the questionnaires are reliable to measure all constructs.

The twelve hypotheses described are statistically evaluated by using two multivariate regression models. The first model is written as follows.

Behavioral Intention $=\beta_{0}+\beta_{1} \cdot$ Performance Expectancy

$+\beta_{2} \cdot$ Effort Expectancy $+\beta_{3}$. Social Influence $+\beta_{4} \cdot$ Gender $+\beta_{5} \cdot$ Age

$+\beta_{6} \cdot$ Performance Expectancy $\cdot$ Gender $+\beta_{7} \cdot$ Effort Expectancy $\cdot$ Gender

$+\beta_{8} \cdot$ Social Influence $\cdot$ Gender $+\beta_{9} \cdot$ Performance Expectancy $\cdot$ Age

$+\beta_{0} \cdot$ Effort Expectancy $\cdot$ Age $+\beta_{1} \cdot$ Social Influence $\cdot$ Age

The second model is written as follows.

Use Behavior $=\beta_{0}^{(2)}+\beta_{1}^{(2)} \cdot$ Facilitatig Conditions $+\beta_{2}^{(2)} \cdot$ Facilitatig Conditions $\cdot$ Age $+\beta_{3}^{(2)} \cdot$ Behavioral Intention

There are few notes regarding the two models. The first model has three independent variables and two interaction variables. Meanwhile, the two models are linked to those twelve hypotheses described previously. Then, the researchers use regression analysis. This is to find the relation between the variables. In this research, there are four independent variables. There are performance expectancy, effort expectancy, social influence, and facilitating condition. Then, there are two dependent variables (behavior intention and use behavior), and two moderating variables (gender and age). The result can be seen in Table 8 and Table 9. After that, the researchers conduct t-test. The results of the t-test on the significance of each coefficient will determine the statistical significance of the twelve hypotheses.
Table 8 The Results of the Regression Analysis for Behavior Intention as the Dependent Variable

\begin{tabular}{lrrr}
\hline \multicolumn{1}{c}{ Variable } & Coefficient & \multicolumn{1}{c}{-stat } & $p$-value \\
\hline Contant & 0,230 & 0,439 & 0,663 \\
Performance & 0,965 & 3,835 & 0,000 \\
Expectancy (PE) & & & \\
Effort Expectancy (EE) & $-0,184$ & $-0,873$ & 0,388 \\
Social Influence (SI) & 0,224 & 1,948 & 0,059 \\
Gender (G) & 3,725 & 0,916 & 0,365 \\
Age (A) & $-0,166$ & $-0,206$ & 0,838 \\
PE $\times$ G & $-0,140$ & $-0,110$ & 0,913 \\
EE $\times$ G & 0,115 & 1,844 & 0,072 \\
SI $\times$ G & $-1,178$ & $-2,373$ & 0,023 \\
PE $\times$ A & $-0,207$ & $-0,617$ & 0,541 \\
EE $\times$ A & 0,381 & 1,205 & 0,236 \\
SI $\times$ A & $-0,189$ & $-1,134$ & 0,264 \\
\hline
\end{tabular}

Table 9 The Results of the Regression Analysis for Use Behavior as the Dependent Variable

\begin{tabular}{lrrr}
\hline \multicolumn{1}{c}{ Variable } & Coefficient & \multicolumn{1}{c}{$t$-stat } & $p$-value \\
\hline Contant & $-0,312$ & $-0,659$ & 0,513 \\
Facilitating Condition & 1,012 & 8,436 & 0,000 \\
$($ FC) & & & \\
FC $\times$ A & 0,014 & 0,292 & 0,772 \\
Behavioral Intention & 0,723 & 12,299 & 0,000 \\
\hline
\end{tabular}

Table 10 The Summary of Regression Test and T-Test

\begin{tabular}{|c|c|c|c|}
\hline Variable & Coefficient & t-stat & $p$-value \\
\hline $\begin{array}{l}\text { Performance } \\
\text { Expectancy }\end{array}$ & 0,965 & 3,835 & 0,000 \\
\hline Effort Expectancy & $-0,184$ & $-0,873$ & 0,388 \\
\hline Social Influence & 0,224 & 1,948 & 0,059 \\
\hline Facilitating Condition & 1,012 & 8,436 & 0,000 \\
\hline Gender & 3,725 & 0,916 & 0,365 \\
\hline Age & $-0,166$ & $-0,206$ & 0,838 \\
\hline $\begin{array}{l}\text { Performance } \\
\text { Expectancy.Gender }\end{array}$ & $-0,140$ & $-0,110$ & 0,913 \\
\hline $\begin{array}{l}\text { Effort Expectancy. } \\
\text { Gender }\end{array}$ & 0,115 & 1,844 & 0,072 \\
\hline Social Influence.Gender & $-1,178$ & $-2,373$ & 0,023 \\
\hline $\begin{array}{l}\text { Performance } \\
\text { Expectancy.Age }\end{array}$ & $-0,207$ & $-0,167$ & 0,541 \\
\hline Effort Expectancy.Age & 0,381 & 1,205 & 0,236 \\
\hline Social Influence.Age & $-0,189$ & $-1,134$ & 0,264 \\
\hline Effort Expectancy.Age & 0,014 & 0,292 & 0,772 \\
\hline $\begin{array}{l}\text { Behavior Intention.Use } \\
\text { Behavior }\end{array}$ & 0,723 & 12,299 & 0,000 \\
\hline
\end{tabular}


From the results presented in Table 10, the researchers conclude that the hypothesis regarding performance expectancy with coefficient of 0,965 has a positive effect on behavior intention. Thus, H1 is accepted. Meanwhile, with coefficient of $-0,140$, there is no positive relation between performance expectancy and behaviour intention which is moderated by gender. Then, $\mathrm{H} 2$ is rejected. Similarly, based on the result of coefficient $(-0,207)$, there is no positive relation between performance expectancy and behaviour intention which is moderated by age. It means $\mathrm{H} 3$ is rejected.

For $\mathrm{H} 4$, the coefficient is $-0,184$. It implies there is no positive relation between effort expectancy and behaviour intention. However, there is positive relation between effort expectancy and behaviour intention which is moderated by gender. Thus H5 is accepted even though it does not has significant effect. It is the same for H6. Effort expectancy has positive and insignificant effect on behaviour intention which is moderated by gender. Then, in H7, the sosial influence has positive and insignificant effect on behaviour intention. Thus $\mathrm{H} 7$ is accepted. However, there is no positive relation between sosial influence and behaviour intention which is moderated by gender. Thus, $\mathrm{H} 8$ is rejected.

With $-0,189$ as the coeffiecient, there is no positive relation between sosial influence and behaviour intention which is moderated by age. Thus, H9 is rejected. Then, for $\mathrm{H} 10$, there is positive relation between facilitating condition and use behaviour. It means $\mathrm{H} 10$ is accepted.

With coeffiecient of 0,014 , there is positive relation between facilitating condition and use behaviour. Therefore, $\mathrm{H} 11$ is accepted. In addition, H12 that behavioral intention has a positive effect on use behavior is also accepted.

The collected empirical data and statistical analysis support the hypotheses that performance expectancy affects positively and significantly on behavioral intention, and facilitating condition has a positive effect on the use behavior. Thus, both of these hypotheses demonstrate that the variables of performance expectancy and facilitating condition are the factors affecting the user in using Bitcoin technology. The construct of performance expectancy is a variable describing the extent to which the user's trust in technology and the level of benefits from the technology usage in terms of ease and speed of transaction. Meanwhile, the construct of facilitating condition describes the extent to which individual trusts the facility, technique and infrastructure for the use of technology. Based on definitions, it means that Bitcoin users have been supported by adequate facilities and infrastructure to access Bitcoin technology. On the other side, the construct effort expectancy does not positively and significantly affect behavior intention. Conversely, the construct behavior intention positively affects the construct use behavior. As the research implications, there are several recommendations. Based on the construct performance expectancy, the companies in engaging its business as a trading center for Bitcoin should increase their security in the transaction process of Bitcoin. They should also pay attention to technical matters in order to maintain the loyalty of Bitcoin users. Meanwhile, in terms of facilitating condition variable, the companies should provide additional facilities. It can be Bitcoin ATM and work in cooperation with many hotels, restaurants, and e-commerce websites to use Bitcoin payment method.

\section{CONCLUSIONS}

The Bitcoin cryptocurrency has gained large traction lately. It provides an alternative with a high level of flexibility to the traditional financial systems. As the number of Bitcoin users in Indonesia is rather low, this research intends to determine the factors affecting the acceptance of the currency. By using the UTAUT model, the sample data collected from a small size of respondents, and the multivariate regression analysis, the researchers find the factors of performance expectancy and facilitating conditions to be determinant. From the results, it can be concluded that performance expectancy and facilitating condition are the main factors affecting the user in using Bitcoin technology. This result implies that in using Bitcoin, the companies should increase its security in the transaction process of Bitcoin, pay attention to technical matters to maintain the loyalty of Bitcoin users, and provide additional facilities.

By considering the limitation in the sample data in this research, the results should be taken with a grain of salt. The research should be assumed as the first initial step to understand what Indonesians think about the currency. Further research by using more respondents is necessary to understand the issue fully.

\section{REFERENCES}

Abdulwahab, L., \& Dahalin, Z. M. (2010). A conceptual model of Unified Theory of Acceptance and Use of Technology (UTAUT) modification with management effectiveness and program effectiveness in context of telecentre. African Scientist, 11(4), 267275.

Androulaki, E., Karame, G. O., Roeschlin, M., Scherer, T., \& Capkun, S. (2013). Evaluating user privacy in Bitcoin. In International Conference on Financial Cryptography and Data Security (pp. 34-51). Springer, Berlin, Heidelberg.

Bohr, J., \& Bashir, M. (2014). Who uses Bitcoin? An exploration of the Bitcoin community. In 2014 Twelfth Annual International Conference on Privacy, Security and Trust (PST) (pp. 94-101). IEEE.

Davis, F. D. (1989). Perceived usefulness, perceived ease of use, and user acceptance of information technology. MIS Quarterly, 319-340.

Fathema, N., Shannon, D., \& Ross, M. (2015). Expanding the Technology Acceptance Model (TAM) to examine faculty use of Learning Management Systems (LMSs) in higher education institutions. Journal of Online Learning \& Teaching, 11(2), 210232.

Feld, S., Schönfeld, M., \& Werner, M. (2014). Analyzing the deployment of Bitcoin's P2P network under an AS-level perspective. Procedia Computer Science, 32, 1121-1126.

Fleder, M., Kester, M. S., \& Pillai, S. (2015). Bitcoin transaction graph analysis. arXiv preprint arXiv:1502.01657.

Lungan, R. (2006). Aplikasi statistika dan hitung peluang. Yogyakarta: Graha Ilmu. 
Moore, T., \& Christin, N. (2013). Beware the middleman: Empirical analysis of Bitcoin-exchange risk. In International Conference on Financial Cryptography and Data Security (pp. 25-33). Springer.

Rogojanu, A., \& Badea, L. (2014). The issue of competing currencies. Theoretical and Applied Economics, 21(1), 1-12.

Scott, A. (2016). These are the world's top 10 Bitcoin-friendly countries. Retrieved from https://news.bitcoin.com/ worlds-top-10-bitcoin-friendly-countries/

Silinskyte, J. (2014). Understanding Bitcoin adoption: Unified Theory of Acceptance and Use of Technology (UTAUT) application (Master Thesis). University Leiden.

Venkatesh, V., Morris, M. G., Davis, G. B., \& Davis, F. D. (2003). User acceptance of information technology: Toward a unified view. MIS Quarterly, 27(3), 425478. 